\title{
Synthesis of Betulin Diacetate and Betulin Dipropionate
}

\author{
Vladimir A. Levdansky ${ }^{\mathrm{a}, \mathrm{b}}$, Alexander A. Kondrasenko ${ }^{\mathrm{a}}$, \\ Alexander V. Levdansky a and Boris N. Kuznetsov*a,b \\ anstitute of Chemistry and Chemical Technology SB RAS \\ FRC "Krasnoyarsk Science Center SB RAS" \\ 50 /24 Akademgorodok, Krasnoyarsk, 660036 Russia \\ ${ }^{b}$ Siberian Federal University \\ 79 Svobodny, Krasnoyarsk, 660041 Russia
}

Received 20.06.2016, received in revised form 12.07.2016, accepted 19.08.2016

It was found that esterification of betulin with acetic and propionic acids in refluxing toluene in the presence of phosphoric acid leads to the formation of betulin 3,28-diacetate and betulin 3,28dipropionate.

Keywords: betulin, esterification, toluene, phosphoric acid, betulin 3,28-diacetate, betulin 3,28dipropionate.

DOI: $10.17516 / 1998-2836-2016-9-3-337-344$.

(C) Siberian Federal University. All rights reserved

* Corresponding author E-mail address: inm@icct.ru 


\title{
Синтез диацетата
}

\section{и дипропионата бетулина}

\author{
В.А. Левданскийа, ${ }^{\mathrm{a}}$, А.А. Кондрасенко ${ }^{\mathrm{a}}$, \\ А.В. Левданский ${ }^{\mathrm{a}}$, Б.Н. Кузнецов ${ }^{\mathrm{a}, \boldsymbol{0}}$ \\ ${ }^{a}$ Институт химии и химической технологии СО РАН \\ ФИЦ «Красноярский научный изентр СО РАН» \\ Россия, 660036, Красноярск, Академгородок, 50/24 \\ ${ }^{6}$ Сибирский федеральный университет \\ Россия, 660041, Красноярск, пр. Свободный, 79
}

Установлено, что этерификачия бетулина уксусной или пропионовой кислотой при кипячении в толуоле в присутствии ортофосфорной кислоты приводит к образованию соответственно 3,28-диацетата бетулина и 3,28-дипропионата бетулина.

Ключевые слова: бетулин, этерификация, толуол, ортофосфорная кислота, 3,28-диацетат бетулина, 3,28-дипропионат бетулина.

\section{Введение}

Эфиры бетулина и других тритерпеноидов лупановой группы, содержащие остатки алифатических и ароматических кислот, имеют разнообразную биологическую активность [1-4]. В работе [4] показано, что ацетаты бетулина обладают гиполипидемическим действием, кроме того, они могут быть использованы для получения полимерных материалов [5]. Пропионовая кислота входит в состав некоторых лекарственных средств: ибупрофена, напроксена и других анальгетиков [5]. Известные способы получения диацилов бетулина в основном заключаются в ацилировании бетулина ангидридами или хлорангидридами соответствующих кислот в среде пиридина [2-4]. Известны способы ацилирования бересты кислотами - уксусной и пропионовой $[5,6]$. Для ацилирования бересты требуется большой расход кислот, массовое соотношение береста : кислота составляет $1: 20$. В результате после перекристаллизации с углем выделяют эфиры бетулина с чистотой не более 90-92 \%. В работе [7] описан двухстадийный способ получения 3,28-дипропионата бетулина. Первая стадия осуществляется путем нагревания смеси бетулина с пропионовой кислотой в автоклаве в атмосфере $\mathrm{N}_{2}$ при температуре $250{ }^{\circ} \mathrm{C}$ в течение 1,5 ч. На второй стадии выделенный и очищенный 28 -пропионат бетулина обрабатывается новой порцией пропионовой кислоты при температуре $70{ }^{\circ} \mathrm{C}$ в течение 3,5 ч. Предложенный способ сложен технологически и требует большого избытка пропионовой кислоты; так, на этерификацию 0,2 г бетулина необходимо 200 мл пропионовой кислоты.

Высокая биологическая активность эфиров бетулина стимулирует разработку простых и эффективных способов их получения. Замена ангидридов и хлорангидридов органических кислот на доступные и дешевые кислоты позволит упростить и удешевить процесс получения сложных эфиров бетулина. 
Для разработки более совершенных методов синтеза диацетата и дипропионата бетулина в настоящей работе изучены реакции ацилирования бетулина уксусной и пропионовой кислотами в среде толуола в присутствии ортофосфорной кислоты.

\section{Экспериментальная часть}

ИК-спектры записаны на Фурье ИК-спектрометре Tensor-27 (Bruker, Германия) в области длин волн 400-4000 см-1 в таблетках $\mathrm{KBr}$ (3 мг образца / 300 мг KBr). Спектры ЯМР сняты на спектрометре Bruker Avance III 600 МГц в $\mathrm{CDCl}_{3}, 0$ - TMC. Элементный анализ выполнен на элементном анализаторе Flash EA ${ }^{\text {тм }}-1112$ (Thermo Quest Italia), одновременно

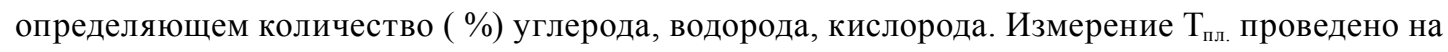
приборе Electrothermal A9100, TCX-анализ осуществлен на пластинках Silufol (Chemapol, Чехия) с использованием системы растворителей хлороформ-метанол, 20:1. Эфиры бетулина обнаруживали 20\%-ным раствором фосфорновольфрамовой кислоты в этаноле с последующим нагреванием при $100-200{ }^{\circ} \mathrm{C}$ в течение 2-3 мин, а также в парах $\mathrm{I}_{2}$. Используемый для этерификации бетулин получен по методике [8]. Толуол был высушен и перегнан над $\mathrm{Na}[9]$.

\section{Синтез 3,28-диацетата бетулина}

В круглодонную колбу объёмом 0,5 л, снабженную прибором для удаления воды, образующейся в ходе реакции (насадка Дина-Старка), помещали 13,26 г (0,03 моль) бетулина, заливали 130 мл толуола, 20 мл ледяной уксусной кислоты и 2 мл 85\%-ной ортофосфорной кислоты, что соответствует $2,6 \%$-ной её концентрации в толуоле. Полученную смесь кипятили до тех пор, пока не выделится рассчитанное по уравнению реакции количество воды (продолжительность 2 ч; выделяется 1,1 мл $\mathrm{H}_{2} \mathrm{O}$ ). Затем реакционную массу концентрировали под вакуумом, остаток разбавляли 150-200 мл воды, образовавшийся осадок отфильтровывали, промывали на фильтре водой, сушили, получая 3,28-диацетата бетулина с выходом 98 \%. После перекристаллизации из этанола выход $83 \%$. $\mathrm{T}_{\text {пл. }} 222-224^{\circ} \mathrm{C}$. Лит.: $\mathrm{T}_{\text {пл. }} 222-223^{\circ} \mathrm{C}[10] . \mathrm{C}_{34} \mathrm{H}_{54} \mathrm{O}_{4}$. Данные элементного анализа соответствовали вычисленным. В табл. 1 приведена зависимость выхода 3,28-диацетата бетулина от концентрации ортофосфорной кислоты и продолжительности реакции.

Таблица 1. Влияние концентрации ортофосфорной кислоты и продолжительности ацилирования бетулина на выход 3,28 -диацетата бетулина

\begin{tabular}{|c|c|c|c|}
\hline № опыта & $\begin{array}{c}\text { Концентрация } \mathrm{H}_{3} \mathrm{PO}_{4} \text { в } \\
\text { толуоле, \% (мл) }\end{array}$ & $\begin{array}{c}\text { Продолжительность } \\
\text { ацилирования, ч }\end{array}$ & $\begin{array}{c}\text { Выход диацетата } \\
\text { бетулина, \% }\end{array}$ \\
\hline 1 & $0,65(0,5)$ & 5,0 & 65 \\
\hline 2 & $1,30(1,0)$ & 4,0 & 77 \\
\hline 3 & $1,95(1,5)$ & 3,0 & 84 \\
\hline 4 & $2,60(2,0)$ & 2,0 & 98 \\
\hline 5 & $3,25(2,5)$ & 2,0 & 97 \\
\hline
\end{tabular}


Таблица 2. Влияние концентрации ортофосфорной кислоты и продолжительности ацилирования бетулина на выход 3,28-дипропионата бетулина

\begin{tabular}{|c|c|c|c|}
\hline № опыта & $\begin{array}{c}\text { Концентрация } \mathrm{H}_{3} \mathrm{PO}_{4} \text { в } \\
\text { толуоле, \% (мл) }\end{array}$ & $\begin{array}{c}\text { Продолжительность } \\
\text { ацилирования, ч }\end{array}$ & $\begin{array}{c}\text { Выход дипропионата } \\
\text { бетулина, \% }\end{array}$ \\
\hline 1 & $0,65(0,5)$ & 6,0 & 68 \\
\hline 2 & $1,30(1,0)$ & 5,0 & 89 \\
\hline 3 & $1,95(1,5)$ & 4,5 & 97 \\
\hline 4 & $2,60(2,0)$ & 4,0 & 97 \\
\hline 5 & $3,25(2,5)$ & 4,0 & 85 \\
\hline
\end{tabular}

\section{Синтез 3,28-дипропионата бетулина}

Получали аналогично 3,28-диацетата бетулина. Выход 3,28-дипропионата бетулина

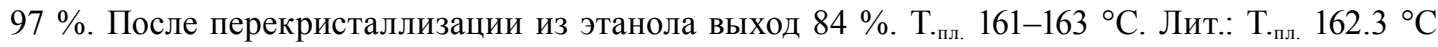
[7]. $\mathrm{C}_{36} \mathrm{H}_{58} \mathrm{O}_{4}$. Данные элементного анализа соответствовали вычисленным. В табл. 2 приведена зависимость выхода 3,28-дипропионата бетулина от концентрации ортофосфорной кислоты и продолжительности реакции.

\section{Результаты и обсуждение}

Известно [11], что при кипячении бетулина в уксусной кислоте в присутствии $\mathrm{H}_{2} \mathrm{SO}_{4}$ образуется 3-ацетат аллобетулина. Позднее в работе [12] было показано, что при замене $\mathrm{H}_{2} \mathrm{SO}_{4}$ на $\mathrm{H}_{3} \mathrm{PO}_{4}$ изомеризации бетулина не происходит и образуется 3,28-диацетат бетулина.

В продолжение работы по этерификации бетулина алифатическими кислотами впервые показано, что ацилирование бетулина уксусной или пропионовой кислотой в присутствии $\mathrm{H}_{3} \mathrm{PO}_{4}$ в среде толуола с удалением воды, выделяющейся в процессе реакции, приводит к образованию 3,28-диацетата бетулина или 3,28 -дипропионата бетулина (рис. 1).

Состав 3,28-диацетата бетулина или 3,28-дипропионата бетулина подтверждены элементным анализом, строение - методами ИК- и ЯМР-спектроскопии. ИК-спектры 3,28-диацетата бетулина или 3,28-дипропионата похожи, в них в отличие от ИК-спектра бетулина появляется интенсивная полоса поглощения $\mathrm{C}=\mathrm{O}$ в области 1735-1738 см-1. В ИК-спектре 3,28-диацетата бетулина характерными являются следующие полосы поглощения $\left(\mathrm{v}, \mathrm{cm}^{-1}\right): 3068,96(\mathrm{C}=\mathrm{C})$; 2948,70; 2871,47 (C-H); 1738,27 (C=O); 1455,94; 1389,48; 1366,64 (C-C); 1244,74; 1151,11; 1106,76 (C-O-C), В ИК-спектре 3,28-дипропионата - $\left(v, \mathrm{~cm}^{-1}\right): 3067,02(\mathrm{C}=\mathrm{C}) ; 2956,98 ; 2871,82(\mathrm{C}-\mathrm{H})$; 1735,$79 ; 1641,88(\mathrm{C}=\mathrm{O}) ; 1461,80 ; 1423,84 ; 1389,97 ; 1355,27$ (C-C); 1276,09; 1261,10; 1185,80; 1148,72; 1105,$54 ; 1083,88$ (C-O-C). Отсутствие полос поглощения в ИК-спектрах 3,28-диацетата бетулина или 3,28-дипропионата бетулина в области 3400-3450 см-1 указывает на полное замещение гидроксильных групп в молекуле бетулина на ацильные группы.

Анализ ЯМР-спектров полученных эфиров бетулина подтвердил их строение. Присутствие в ${ }^{1} \mathrm{H}$ ЯМР-спектре сигналов протонов в области 4.72 и 4.55 м.д. для 3,28-диацетата бетулина и в области 4.71 и 4.61 м.д. для 3,28-дипропионата бетулина свидетельствует об устойчивости концевой двойной связи к изомеризации и окислению в выбранных условиях проведения 


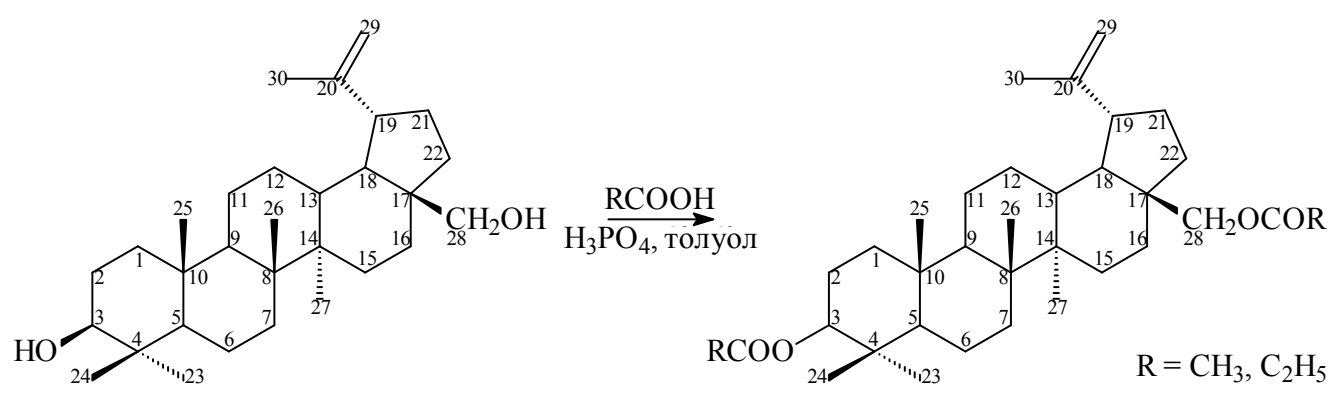

Рис. 1. Схема синтеза 3,28-диацетата и 3,28-дипропионата бетулина

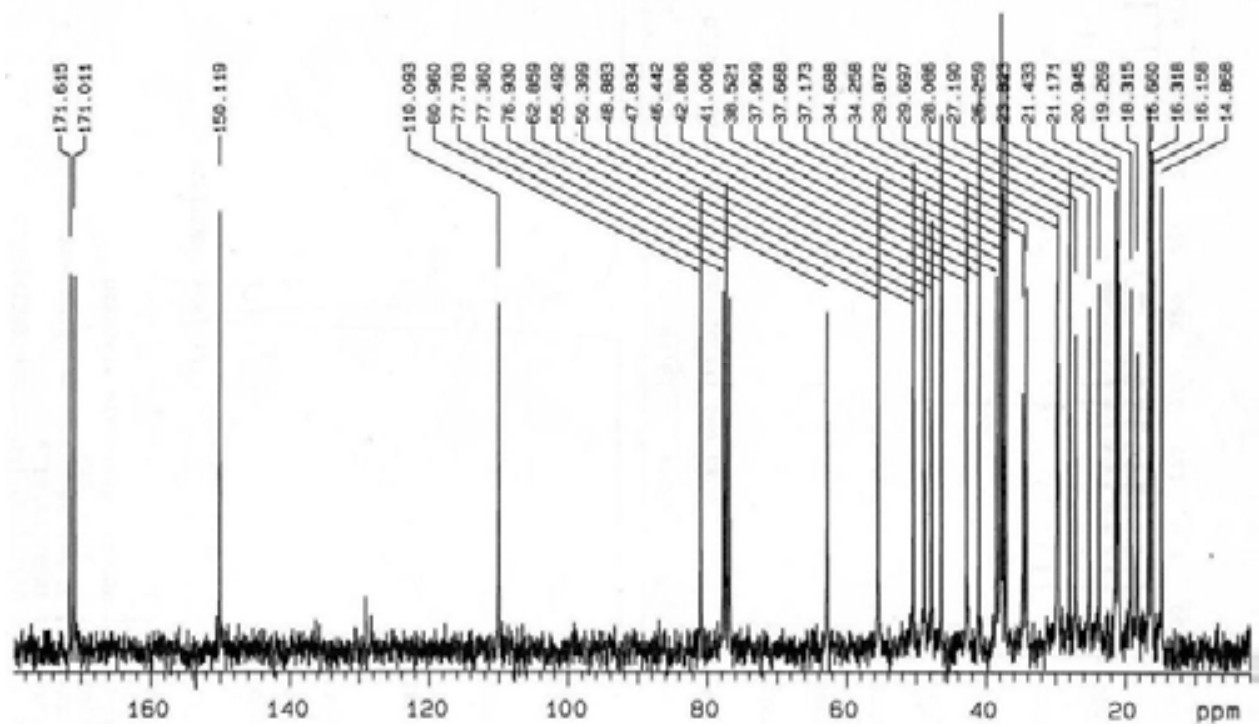

Рис. 2. ${ }^{13} \mathrm{C}$ ЯМР-спектр 3,28-диацетата бетулина

реакции. Спектр 'Н ЯМР диацетата бетулина $\left(\mathrm{CDCl}_{3}\right.$, м.Д., $\left.\delta\right): 4.72\left(1 \mathrm{H}, \mathrm{M},=\mathrm{CH}_{2}\right) ; 4.55(1 \mathrm{H}, \mathrm{м}$, $\left.=\mathrm{CH}_{2}\right) ; 4.47$ (1H, м, Н3); 4.26 (1Н, д, J10,7 Гц, Н28); 3.86 (1Н, д, J10,7 Гц, Н28); 2.50 (1Н, м, Н19); $2.08\left(3 \mathrm{H}, \mathrm{c}, \mathrm{CH}_{3} \mathrm{CO}\right) ; 2.03$ (3H, c, $\left.\mathrm{CH}_{3} \mathrm{CO}\right) ; 1.65 ; 1.02 ; 0,94 ; 0,82 ; 0,80$ (все $3 \mathrm{H}, \mathrm{c}, \mathrm{CH}_{3}$ ), что соответствует данным, приведенным в работе [12]. Спектр ${ }^{1} \mathrm{H}$ ЯМР дипропионата бетулина $\left(\mathrm{CDCl}_{3}\right.$, м.д., б): $4.71 \mathrm{~m}\left(1 \mathrm{H},=\mathrm{CH}_{2}\right) ; 4.61 \mathrm{~m}\left(1 \mathrm{H},=\mathrm{CH}_{2}\right) ; 4.49 \mathrm{dd}(\mathrm{J} 10,75 г ц, \mathrm{~J} 5.65 г ц, \mathrm{H}-3) ; 4.29 \mathrm{dd}(1 \mathrm{H}, \mathrm{J}$ 12.1гц, J 1.4гц, Н-28); 3.87 d (1H, J 12.1 гц, Н-28); 2.49(1H, ddd, J 11.2, J 11.2, J 5.76 гц, Н-9); 2.37(2H, q, J 7.56гц, H-32); 2.345 q,2.347 (2H, J 35,36 7.56гц, , H-35); 1.70s(3H,H-30 ); 1.18 t, $1.17 \mathrm{t}\left(6 \mathrm{H}, 2 \mathrm{CH}_{3}\right.$, $\mathrm{J} 32,33=\mathrm{J} 35,36$ 7.76гц, Н-33 и Н-36 ); 1.16s, 0,99s, 0,88s 0,86s, 0,86s $\left(15 \mathrm{H}, 5 \mathrm{CH}_{3}, \mathrm{H}-23, \mathrm{H}-24, \mathrm{H}-25\right.$, Н-26, Н-27), что соответствует данным, приведенным в работе [5].

В спектре ${ }^{13} \mathrm{C}$ ЯМР (рис. 2) присутствуют сигналы 34 атомов углерода, а в ${ }^{13} \mathrm{C}$ ЯМР-спектре 3,28-дипропионата бетулина (рис. 3) - 36 атомов углерода, что соответствует их бруттоформулам $\mathrm{C}_{34} \mathrm{H}_{52} \mathrm{O}_{4}$ и $\mathrm{C}_{36} \mathrm{H}_{56} \mathrm{O}_{4}$.

Известно, что химический сдвиг атома углерода С3 бетулина, связанного с гидроксильной группой, наблюдается при 78-79 м.д., а сигнал атома углерода С28 - при 59-60 м.д. [13]. Анализ 


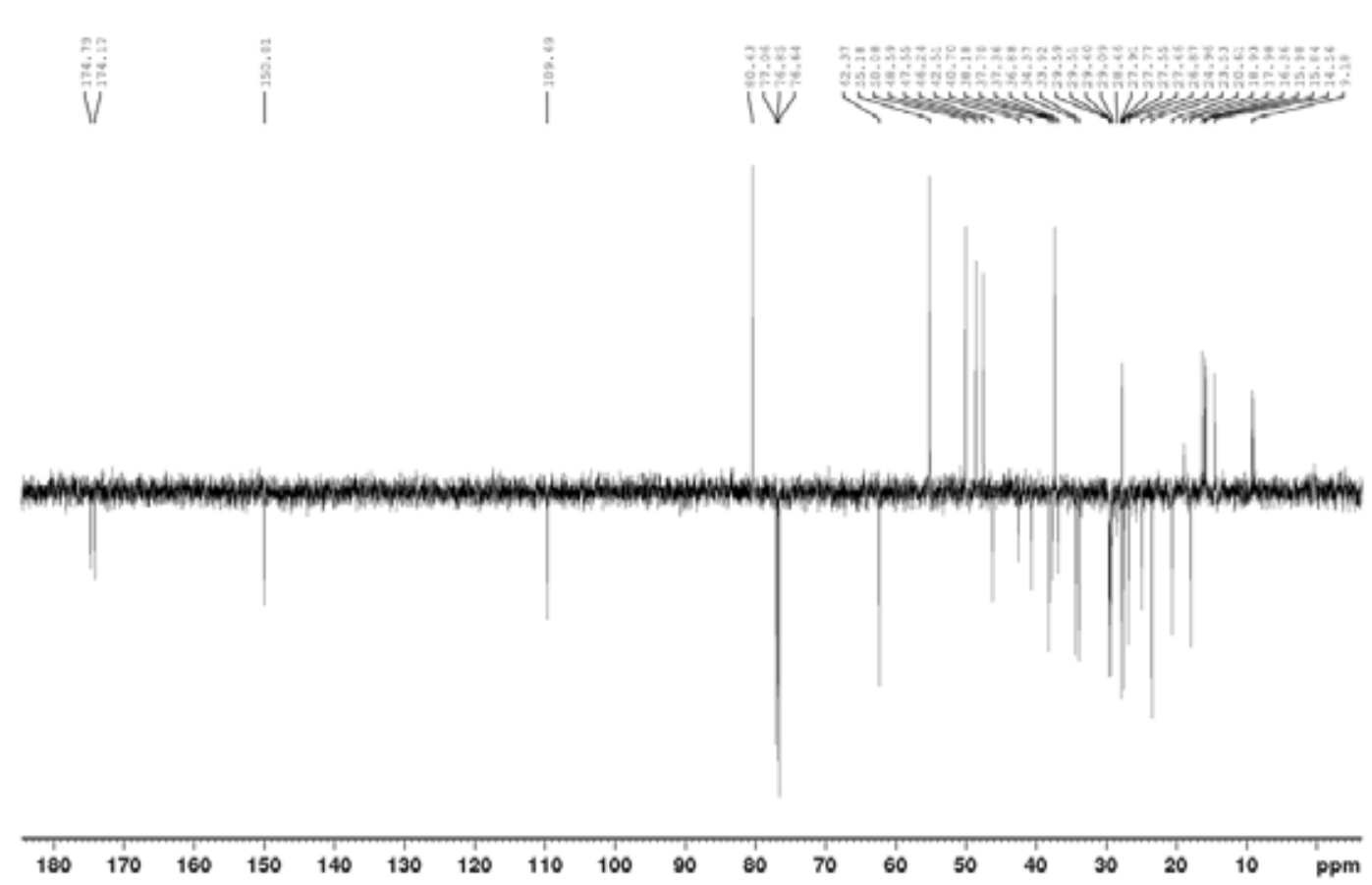

Ри. 3. ${ }^{13}$ С ЯМР-спектр 3,28-дипропионата бетулина

${ }^{13} \mathrm{C}$ ЯМР-спектров 3,28-диацетата бетулина и 3,28-дипропионата бетулина показал, что после ацилирования химический сдвиг атома углерода С3 смещается в слабое поле к 80-81 м.д., а атома углерода С28 - к 62-63 м.д., что подтверждает присутствие ацильных групп в полученных эфирах бетулина.

\section{Заключение}

Впервые показано, что этерификация бетулина уксусной или пропионовой кислотой в присутствии ортофосфорной кислоты с удалением воды, выделяющейся в процессе реакции, приводит к образованию соответственно 3,28-диацетата и 3,28-дипропионата бетулина. Состав полученных веществ подтвержден элементным анализом, а строение - методами ИК- и ЯМР-спектроскопии.

\section{Благодарности}

Работали с приборами Красноярского регионального центра коллективного пользования CO PAH.

\section{Список литература}

1. Толстиков Г.А., Флехтер О.Б., Шульц Э.Э., Балтина Л.А., Толстиков А.Г. Бетулин и его производные. Химия и биологическая активность. Хим. интер. устойч. разв. 2005. Т. 13(1), C. 1-30, [Tolstikov G.A., Flekhter O.B., Shultz E.E., Baltina L.A., Tolstikov A.G. Betulin and its derivatives. Chemistry and biological activity. Chemistry for Sustainable Development. 2005. Vol. 13(1), P. 1-29.]. 
2. Флехтер О.Б., Медведева Н.И., Карачурина Л.Т., Балтина Л.А., Галин Ф.З., Зарудий Ф.С., Толстиков Г.А. Синтез и фармакологическая активность эфиров бетулина, бетулиновой кислоты и аллобетулина. Хим.-фарм. журн., 2005. Т.39(8), С. 9-12. [Flekhter O.B., Medvedeva N.I., Karachurina L.T., Baltina L.A., Galin F.Z., Zarudii F.S., Tolstikov G.A. Synthesis and pharmacological activity of betulin, betulinic acid, and allobetulin esters. Pharm. Chem. J. 2005. Vol. 39(8), P. 401404.].

3. Chue K.-T., Chang M.-S., Ten L. N., Synthesis and antibacterial activity of betulin esters. Chem. Nat. Comp., 2011. Vol. 47(4), P. 583-586.

4. Флехтер О.Б., Карачурина Л.Т., Поройков В.В., Нигматуллина Л.Р., Балтина Л.А., Зарудий Ф.С., Давыдова В.А., Спирихин Л.В., Байкова И.П., Галин Ф.З., Толстиков Г.А. Синтез эфиров тритерпеноидов группы лупана и их гепатопротекторная активность. Биоорг. химия. 2000, T.26(3), C. 215-223. [Flekhter O.B., Karachurina L.T., Poroikov V.V., Nigmatullina L.R., Baltina L.A, Zarudii F.S., Davydova V.A., Spirikhin L.V., Baikova I.P., Galin F.Z., Tolstikov G.A. The synthesis and hepatoprotective activity of esters of the lupane group triterpenoids. Russ. J. Bioorg. Chem. J. 2000, Vol. 26(3), P. 192-200,].

5. Кузнецова С.А., Скворцова Г.П., Маляр. Ю.Н., Соколенко В.А., Кузнецов Б.Н. Синтез дипропионата бетулина из бересты коры берёзы. Хим. растит. сырья. 2011. (4), С. 77-82. [Kuznetsova S.A., Skvortsova G.P., Maljar Yu.N., Sokolenko V.A., Kuznetsov B.N. Synthesis of betulin diacetate and betulin dipropionate from birch bark. Chemistry of plant raw materials. 2011. (4), P. 77-82. (in Russ.)]

6. Кузнецова С.А., Васильева Н.Ю., Калачева Г.С., Титова Н.М., Редькина Е.С., Скворцова Г.П. Получение диацетата бетулина из бересты коры березы и изучение его антиоксидантной активности. Журн. Сиб. федер. ун-т. Химия, 2008. Т. 1(2), С. 151-165. [Kuznetsova S.A., Vasil'eva N.Yu., Kalacheva G.S., Titova N.M., Red kina E.S., Skvortsova G.P. Obtaining betulin diacetate from the outer birch bark and studying it's antioxidant activity. J. SFU. Chemistry. 2008. Vol. 1(2), P. 151165. (in Russ.)].

7. Patent 2001288222 JP. Tabata M., Sano Y., Ichikawa A. Polymer obtained from betulin and its production method. Publ. Date 16.10,2001.

8. Левданский В.А., Левданский А.В., Экстракция бетулина алифатическими спиртами $\mathrm{C}_{3}-\mathrm{C}_{4}$ из бересты березы, гидролизованной в водном растворе щелочи. Хим. растит. сырья. 2014. (1), C. 131-137. [Levdansky V.A., Levdansky A.V. Extraction of betulin by aliphatic alcohols $\mathrm{C}_{3}-\mathrm{C}_{4}$ from an external layer of birch bark hydrolyzed in aqueous alkaline solution. Chemistry of plant raw materials. 2014. (1), P. 131-137. (in Russ.)].

9. Gordon A.J., Ford R.A., The chemist's companion: a handbook of practical data, techniques, and references. New York: A Wiley-Interscience publication, 1972, $537 \mathrm{p}$.

10. Пегова Р.А., Жильцова О.Е., Клабукова И.Н., Мухина И.В., Лапшин Р.Д., Жданович И.В., Мельникова Н.Б. Фармацевтические композиции гиполипидемического действия эфиров уксусной и янтарной кислот бетулина. Медицинский альманах, 2015. T. 38(3), C. 216-219. [Pegova R.A., Zhiltsova O.E., Klabukova I.N., Mukhina I.V., Lapshin R.D., Zhdanovich I.V., Melnikova N.B. Pharmaceutical compositions of hypolipidemic effect of esthers of acetic acid and amber acid of betulin. Medicinskij al'manah. 2015. Vol. 38(3), P. 216-219. (in Russ.)]. 
11. Barton D. H. R., Holness N. J. 18. Triterpenoids. Part V. Some relative configurations in rings C, D, and E of the $\beta$-amyrin and the lupeol group of triterpenoids. J. Chem. Soc., 1952. P. 78-92.

12. Левданский В.А., Левданский А.В., Кузнецов Б.Н., Влияние ортофосфорной кислоты на химические превращения бетулинола в бутаноле, изобутаноле и уксусной кислоте. Журн. Сиб. федер. ун-т. Химия, 2008. Т. 1(4), С. 369-375. [Levdansky V.A., Levdansky A.V., Kuznetsov B.N. Influence of orthophosphoric acid on chemical transformations of betulinol in butanol, isobutanol, and an acetic acid. J. SFU. Chemistry. 2008. Vol. 1(4), P. 369-375. (in Russ.)].

13. Levdansky V.A., Levdansky A.V., Kuznetsov B.N. Sulfation of betulin with chlorosulfonic acid in dimethylformamide and dioxane. Russ. J. Bioorg. Chem. 2014. Vol. 40(7), P. 748-751. 